\title{
LixiviaçÃo E Persistência dos Herbicidas Sulfentrazone E IMAZAPIC ${ }^{1}$
}

Leaching and Persistence of Sulfentrazone and Imazapic

\begin{abstract}
MONQUERO, P.A. ${ }^{2}$, SILVA, P.V. ${ }^{3}$, SILVA HIRATA, A.C. ${ }^{4}$, TABLAS, D.C. ${ }^{3}$ e ORZARI, I. ${ }^{3}$
RESUMO - Em razão da escassez de informações quanto ao potencial de movimentação do sulfentrazone e imazapic em solos brasileiros, objetivou-se neste trabalho avaliar a lixiviação e a persistência desses herbicidas. A lixiviação de sulfentrazone $\left(800 \mathrm{~g} \mathrm{ha}^{-1}\right)$ e imazapic $\left(210 \mathrm{~g} \mathrm{ha}^{-1}\right)$ foi avaliada sob simulação de chuva de 40 e $80 \mathrm{~mm}$, em diferentes profundidades $(5,10,15,20,25,30,35$ e $40 \mathrm{~cm})$ e pHs de um Latossolo Vermelho Distroférrico e Latossolo Vermelho Distrófico. O ensaio de persistência consistiu da aplicação dos herbicidas sulfentrazone (600 e $\left.800 \mathrm{~g} \mathrm{ha}^{-1}\right)$ e imazapic (190 e $210 \mathrm{~g} \mathrm{ha}^{-1}$ ) em pré-emergência, além da testemunha sem herbicidas. Foram retiradas amostras de solo para determinação da persistência aos $0,15,30,45,60,90,120,150$ e 210 dias após a aplicação, sendo posteriormente levadas a um fitotron para crescimento do bioindicador Cucumis sativus. A lixiviação dos herbicidas foi mais pronunciada à medida que se aumentou a quantidade de chuva simulada. Para o sulfentrazone, na precipitação de $80 \mathrm{~mm}$, foi constatada atividade residual até $40 \mathrm{~cm}$ de profundidade, sendo elevada no solo de textura média e menos pronunciada no de textura argilosa, independentemente do pH. Em relação ao imazapic na precipitação de $80 \mathrm{~mm}$ de chuva, houve atividade do herbicida até $40 \mathrm{~cm}$ de profundidade. No solo argiloso com pH 6,0 houve maior lixiviação em todas as profundidades, em relação ao mesmo solo com pH 4,7. Quanto à persistência, observou-se que o sulfentrazone e imazapic apresentaram atividade residual semelhante até 45 DAA, todavia, dos 60 aos 150 DAA, houve menor atividade do imazapic no solo; a partir deste periodo (150 aos 210 DAA), o sulfentrazone apresentou redução acentuada de sua atividade no solo.
\end{abstract}

Palavras-chave: bioensaio, efeito residual, mobilidade, solo.

ABSTRACT - Considering the lack of information on sulfentrazone and imazapic leaching in Brazilian soils, this work aimed to evaluate leaching and persistence of these herbicides. Leaching of sulfentrazone (800 g a.i. $\left.\mathrm{ha}^{-1}\right)$ and imazapic $\left(210 \mathrm{~g}\right.$.a.i. $\left.\mathrm{ha}^{-1}\right)$ was evaluated under simulated rainfall equivalent to 40 and $80 \mathrm{~mm}$ at different depths $(5,10,15,20,25,30,35$ and $40 \mathrm{~cm})$ and soil $\mathrm{pH}$ of a Dystroferric Red Latosol and Dystrophic Red Latosol. The persistence assay consisted of sulfentrazone (600 and $\left.800 \mathrm{~g} \mathrm{ha}^{-1}\right)$ and imazapic (190 and $210 \mathrm{~g} \mathrm{ha}^{-1}$ ) application during weed pre-emergence, as well as a weeded check. Soil samples were collected for herbicide persistence determination at $0,15,30,45,60,90,120,150$ and 210 days after application and were subsequently placed in a phytotron for bioindicator Cucumis sativus growth. Herbicide leaching was more pronounced as simulated rainfall was increased. Residual activity of sulfentrazone under $80 \mathrm{~mm}$ rainfall simulation was verified up to $40 \mathrm{~cm}$ depth, being more pronounced in medium textured rather than clayey soils, independently of soil pH. In relation to imazapic under $80 \mathrm{~mm}$ rainfall, herbicide activity was observed up to $40 \mathrm{~cm}$ depth. In the clayey soil with $p H$ 6.O, leaching was higher at all depths, compared to leaching of the same soil with $\mathrm{pH}$ 4.7. As for persistence, sulfentrazone and imazapic were found to present similar residual activity up to 45 DAA; however, from 60 to 150 DAA, imazapic presented lower residual activity in the soil, and after this period (150 to 210 DAA), sulfentrazone presented a marked residual reduction.

Keywords: bioassay, residual effect, mobility, soil.

Recebido para publicação em 19.6.2009 e na forma revisada em 12.3.2010.

2 Professora adjunta do Centro de Ciências Agrárias/UFSCar e do Programa de Pós-Graduação Agricultura e Ambiente, Rodovia Anhanguera, km 174, 13600-970 Araras-SP, <pamonque@cca.ufscar.br>; ${ }^{3}$ Alunos de graduação do Centro de Ciências Agrárias/ UFSCar; ${ }^{4}$ Pesquisadora científica do Pólo Regional da Alta Sorocabana, Rodovia Raposo Tavares, km 561 Caixa Postal 298, 19015-970 Presidente Prudente-SP. 


\section{INTRODUÇÃO}

Devido ao seu uso intensivo, os herbicidas são frequentemente detectados em estudos de qualidade de águas superficiais e subterrâneas (Carter, 2000; Tanabe et al., 2001). Nas áreas próximas ao cultivo de cana-de-açúcar registra-se maior ocorrência de resíduos desses compostos, já que essa é uma das culturas que mais utilizam herbicidas no manejo de plantas infestantes ou plantas daninhas (Southwick et al., 2002; Vivian et al., 2007).

O processo de lixiviação é a principal forma de transporte no solo das moléculas não voláteis e solúveis em água. Essas moléculas deslocam-se no perfil do solo, acompanhando o fluxo de água, o qual é governado pela diferença de potencial de água entre dois pontos (Prata et al., 2003). A lixiviação é fundamental para a incorporação superficial da maioria dos herbicidas, atingindo sementes ou plantas em germinação, mas, quando excessiva, pode carreá-los para camadas mais profundas do solo, limitando sua ação e podendo, inclusive, promover contaminação do lençol freático (Velini, 1992).

Esses processos são dependentes do tipo de solo, das condições climáticas e das características dos produtos. O conhecimento desses fatores é de fundamental importância para prever o comportamento de herbicidas nas diferentes classes de solo e para seleção de dosagens adequadas, bem como para evitar efeitos prejudiciais ao ambiente e às culturas subsequentes (Rossi et al., 2005).

O movimento descendente dos herbicidas no solo é influenciado pelo teor e tipo de matéria orgânica, composição, tamanho e distribuição das partículas do solo, $\mathrm{pH}$ e densidade do solo, tamanho e distribuição dos poros, além da solubilidade em água das moléculas dos herbicidas e do índice de precipitação pluvial (Prata et al., 2003).

Para herbicidas de elevada capacidade adsortiva, o conteúdo de matéria orgânica do solo é geralmente um fator importante, pois, quanto mais alto, maior será a adsorção do herbicida e, com isso, menor a lixiviação. Em solos arenosos, a lixiviação será ainda maior do que em solos siltosos ou argilosos (Rossi et al., 2005).
Resultados obtidos por Inoue et al. (2002) evidenciaram que o incremento no nivel de calagem proporcionou significativo aumento do potencial de lixiviação de imazaquin (150 $\mathrm{g} \mathrm{ha}^{-1}$ ) nas colunas de Latossolo Vermelho Distrófico e Latossolo Roxo Distroférrico. Assim, niveis mais elevados de calagem apresentam maior potencial de lixiviação desse herbicida do que os niveis mais baixos. Rocha et al. (2000) observaram que a elevação do $\mathrm{pH}$ também diminuiu em grande intensidade a sorção de imazaquin em um Latossolo Vermelho Acriférrico.

Para solos de clima temperado, a sorção do imazaquin está positivamente correlacionada com o teor de matéria orgânica e negativamente com o pH da solução do solo (Loux et al., 1989; Regitano et al., 1997). Regitano et al. (1997) observaram, para seis solos com cargas dependentes de $\mathrm{pH}$ e doze com cargas permanentes, que o principal mecanismo envolvido na sorção de imazaquin foi a partição hidrofóbica. Entretanto, nos sítios do solo com carga positiva, como na superficie dos óxidos de $\mathrm{Fe}$ e $\mathrm{Al}$, houve expressiva sorção do produto, devido a mecanismos de troca aniônica e/ou formação de ligantes, principalmente em solos com baixo teor de carbono orgânico.

Em solos com baixo teor de matéria orgânica e CTC efetiva, verificou-se, por exemplo, o aumento na ocorrência de efeitos fitotóxicos do s-metolachlor às culturas e na probabilidade de contaminação de águas subterrâneas (Procópio et al., 2001).

Rossi et al. (2005), utilizando como plantateste o sorgo (Sorghum bicolor) para avaliar a lixiviação do sulfentrazone em dois tipos de solo, submetidos a diferentes regimes pluviométricos, determinaram que sob precipitação de $90 \mathrm{~mm}$ o herbicida foi detectado até $12,5 \mathrm{~cm}$ de profundidade na coluna contendo Nitossolo Vermelho.

O material de origem do solo, os tipos de minerais predominantes na fração argila, os grupos funcionais e a quantidade da matéria orgânica, além das condições climáticas do local onde o herbicida foi aplicado, são responsáveis pelas variações na mobilidade de herbicidas nos solos (Weber et al., 2004). Para uso seguro de herbicidas, além do conhecimento 
dessas características, é necessário conhecer a duração de sua atividade, o processo de controle de sua persistência e a sua seletividade entre as culturas e plantas daninhas (Blanco, 1979).

O herbicida sulfentrazone possui excelente atividade pré-emergente no solo para controle de plantas daninhas dicotiledôneas e diversas espécies monocotiledôneas (FMC, 1995), sendo amplamente utilizado no controle de plantas daninhas em cana-de-açúcar e também de biótipos resistentes à acetolactato sintase - ALS, na cultura da soja (Hulting et al., 2001). Ele possui registro para culturas de grande importância comercial para o Brasil, como a cana-de-açúcar, a soja e o eucalipto. A sua meia-vida no solo ( $t 1 / 2)$ é estimada entre 110 e 280 dias, variando a partir das condições edafoclimáticas locais, sendo a atividade microbiológica seu mecanismo inicial de degradação (FMC, 1995). Ademais, possui baixa dissociação em água, comportando-se como ácido fraco $(\mathrm{pKa}=6,56)$, e sua solubilidade aumenta com o aumento do $\mathrm{pH}(\mathrm{pH} \mathrm{6,0}=$ $110 \mathrm{mg} \mathrm{L}^{-1} ; \mathrm{pH} 7,5=1.600 \mathrm{mg} \mathrm{L}^{-1}$ ), encontrando-se predominantemente na solução do solo na forma não ionizada (FMC, 1995).

O herbicida imazapic apresenta ação em pré e pós-emergência, com translocação apossimplástica, sendo recomendado para o controle de gramineas, folhas largas e perenes de dificil controle, como $C$. rotundus e Cynodon dactylon. A sua meia-vida no solo ( $\left.\mathrm{t}^{1} / 2\right)$ é maior que 180 dias, variando a partir das condições edafoclimáticas locais, sendo a atividade microbiológica seu mecanismo inicial de degradação (Rodrigues \& Almeida, 2005). É um herbicida de caráter ácido $(\mathrm{pKa}=3,9)$ e com solubilidade de $2.200 \mathrm{mg} \mathrm{L}^{-1}$ a $25^{\circ} \mathrm{C}$. Ensaios de lixiviação com imazapic em diferentes tipos de solo mostraram que o produto apresenta mobilidade intermediária (Rodrigues \& Almeida, 2005). Regitano et al. (1997) investigaram a contribuição de alguns atributos do solo - como o $\mathrm{pH}$, o carbono orgânico, a argila e a CTC na sorção do imazaquin - e observaram que o $\mathrm{pH}$ e o teor de carbono orgânico foram os principais atributos relacionados à retenção do herbicida. Ao estudar a persistência e lixiviação do imazapyr em dois solos com diferentes características físicas e químicas, Vizantinopoulos \& Lolos (1994) constataram elevada mobilidade dessa molécula nos solos e concluíram que esse processo é influenciado pelo $\mathrm{pH}$, teor de argila e conteúdo de matéria orgânica.

Em razão da escassez de informações quanto ao potencial de movimentação do sulfentrazone e imazapic em solos brasileiros, evidencia-se a necessidade de pesquisas sobre o comportamento desses herbicidas em solos cultivados. Além disso, em função da persistência de sulfentrazone e imazapic e dos possiveis danos em culturas cultivadas após a aplicação desses herbicidas, o objetivo deste trabalho foi avaliar, em colunas de solo, o potencial de lixiviação de sulfentrazone e imazapic, o efeito residual desses herbicidas e a influência de períodos crescentes de estiagem sobre a ação desses produtos.

\section{MATERIAL E MÉTODOS}

\section{Ensaio de lixiviação}

O experimento foi conduzido em casa de vegetação, no Centro de Ciências Agrárias/ UFSCar, Araras-SP. As amostras foram retiradas de dois solos: Latossolo Vermelho Distroférrico e Distrófico (Embrapa, 1999), nas profundidades de 0-10, 10-20, 20-30 e $30-40 \mathrm{~cm}$. A análise química foi feita pelo Laboratório de Química e Fertilidade do Solo do Centro de Ciências Agrárias/UFSCar (Tabela 1). Foi incluído no experimento o solo de textura média com menor quantidade de matéria orgânica para comparação (Latossolo Vermelho Distrófico). A metodologia utilizada foi desenvolvida por Inoue et al. (2002), com algumas modificações.

Amostras do Latossolo Vermelho Distroférrico, na profundidade de $0-20 \mathrm{~cm}$, foram acondicionadas em sacos plásticos, sendo adicionados diferentes niveis de calcário. Foi calculada e adicionada à terra contida nos sacos plásticos uma quantidade de calcário dolomítico (PRNT=80\%) suficiente para elevar o $\mathrm{pH}$ a 6,0 (pH confirmado com análise de solo). Após mistura e homogeneização do calcário ao solo, as amostras foram mantidas, durante os 90 dias subsequentes, com umidade suficiente para permitir a reação de neutralização do solo. Assim, foi estudada a lixiviação dos herbicidas em solo argiloso com 
Tabela 1 - Características químicas e físicas das amostras dos solos utilizados no experimento

\begin{tabular}{|c|c|c|c|c|c|c|c|c|c|c|c|c|c|}
\hline \multirow{2}{*}{ Amostra } & $\mathrm{pH}$ & $\mathrm{MO}$ & $\mathrm{P}$ & $\mathrm{K}$ & $\mathrm{Ca}$ & $\mathrm{Mg}$ & $\mathrm{Al}$ & \multirow[t]{2}{*}{ SB } & CTC & \multirow{2}{*}{$\begin{array}{c}\mathrm{V} \\
(\%) \\
\end{array}$} & \multirow{2}{*}{\multicolumn{3}{|c|}{\begin{tabular}{c|c} 
Argila & Silte \\
& $\left(\mathrm{g} \mathrm{kg}^{-1}\right)$
\end{tabular}}} \\
\hline & $\left(\mathrm{CaCl}_{2}\right)$ & $\left(\mathrm{g} \mathrm{dm}^{-3}\right)$ & $\left(\mathrm{mg} \mathrm{dm}^{-3}\right)$ & \multicolumn{4}{|c|}{$\left(\mathrm{mmol}_{\mathrm{c}} \mathrm{dm}^{-3}\right)$} & & & & & & \\
\hline \multicolumn{14}{|l|}{ LVdf } \\
\hline $0-10$ & 4,7 & 26 & 4 & 0,8 & 20 & 9 & 0 & 29,8 & 58,8 & 51 & 560 & 240 & 200 \\
\hline $10-20$ & 4,7 & 24 & 2 & 0,7 & 18 & 8 & 0 & 26,7 & 55,7 & 48 & 590 & 220 & 190 \\
\hline $20-30$ & 5,4 & 18 & 3 & 2,3 & 16 & 7 & 0 & 25,3 & 51,3 & 49 & 620 & 190 & 190 \\
\hline $30-40$ & 5,6 & 16 & 2 & 1,6 & 12 & 4 & 0 & 17,6 & 42,6 & 41 & 620 & 190 & 190 \\
\hline \multicolumn{14}{|l|}{ LVd } \\
\hline $0-10$ & 5,3 & 22 & 12 & 2,3 & 28 & 11 & 0 & 40,9 & 68,9 & 63 & 320 & 170 & 510 \\
\hline $10-20$ & 5,3 & 20 & 8 & 2,0 & 20 & 10 & 0 & 32,0 & 57,0 & 56 & 370 & 160 & 470 \\
\hline $20-30$ & 5,4 & 15 & 8 & 2,1 & 18 & 8 & 0 & 28,1 & 52,1 & 54 & 400 & 150 & 450 \\
\hline $30-40$ & 5,5 & 14 & 6 & 1,8 & 14 & 6 & 0 & 21,8 & 45,8 & 47 & 420 & 170 & 450 \\
\hline
\end{tabular}

LVdf - Latossolo Vermelho Distroférrico. LVd - Latossolo Vermelho Distrófico.

pH de 4,7 e 6,0, além do solo com textura média, com $\mathrm{pH}$ de 5,3 .

O delineamento foi inteiramente ao acaso, com quatro repetições. As unidades experimentais foram colunas de solos montadas em tubos de PVC de $10 \mathrm{~cm}$ de diâmetro e $50 \mathrm{~cm}$ de comprimento, na ordem de profundidade em que foram retiradas do perfil do solo. Os tubos foram envoltos internamente com uma camada de parafina, a fim de evitar escorrimento lateral da solução do solo. Na parte basal, para reter o solo e permitir a drenagem, foram colocadas telas de sombrite $50 \%$. Após o preenchimento, foi colocada na extremidade superior da coluna de solo uma camada de lã de vidro, combinada com papel-filtro, com a função de reduzir o impacto das gotas e de garantir a uniformidade na distribuição dos fluidos. As colunas de solo foram, então, submetidas à irrigação por capilaridade, até ele se apresentar saturado no topo, permitindose em seguida o escoamento da água durante 48 horas, para restaurar sua capacidade de campo.

Foram aplicados os herbicidas sulfentrazone (800 $\left.\mathrm{g} \mathrm{ha}^{-1}\right)$ e imazapic (210 $\left.\mathrm{g} \mathrm{ha}^{-1}\right)$ quando os solos das colunas se apresentavam na capacidade de campo. Os tratamentos foram arranjados em esquema fatorial $3 \times 8$, sendo três pHs e oito profundidades de análise, avaliados dentro de cada herbicida. Os herbicidas foram aplicados com pulverizador costal pressurizado com $\mathrm{CO}_{2}$, provido de barra de pulverização contendo dois bicos tipo leque
Teejet 110.02 e com volume de calda de $200 \mathrm{~L} \mathrm{ha}^{-1}$.

Logo após a aplicação dos herbicidas, os tubos foram colocados sob simulador de chuva, com intensidade de precipitação de $1 \mathrm{~mm} \mathrm{m^{-1 }}$, durante o tempo necessário para aplicar a lâmina de água de 40 e $80 \mathrm{~mm}$. Após a simulação, as colunas ficaram em repouso por 72 horas, quando então foram abertas e colocadas na posição horizontal. Cada coluna foi dividida em oito seções de $5 \mathrm{~cm}$, medidas a partir da superficie onde os herbicidas foram aplicados. Em cada seção foi semeada uma linha contínua de sementes de pepino (Cucumis sativus), cuja planta é bioindicadora da presença dos herbicidas avaliados. Nas figuras, cada intervalo de $5 \mathrm{~cm}$ é representado numericamente pelo maior valor.

Aos 21 dias após a semeadura, foram avaliados nas plântulas de Cucumis sativus os sintomas de intoxicação dos herbicidas avaliados. Essas avaliações foram baseadas em critérios qualitativos, segundo a ALAM (1974), que utiliza uma escala percentual de notas, em que 0 (zero) corresponde a nenhuma injúria na planta e 100 (cem) à morte das plantas. Além da análise visual, também foi determinada aos 21 DAT a biomassa das plantas bioindicadoras.

\section{Ensaio de persistência}

O ensaio de persistência foi também avaliado em Latossolo Vermelho Distroférrico, 
em uma área plana, sem histórico de aplicação de herbicidas residuais, por pelo menos quatro anos. A análise química do solo é apresentada na Tabela 2 .

O ensaio constituiu da aplicação dos herbicidas sulfentrazone (600 e $\left.800 \mathrm{~g} \mathrm{ha}^{-1}\right)$ e imazapic ( 190 e $210 \mathrm{~g} \mathrm{ha}^{-1}$ ) em pré-emergência das plantas daninhas, além da testemunha sem herbicidas. Os herbicidas foram aplicados separadamente com pulverizador costal pressurizado com $\mathrm{CO}_{2}$, provido de barra de pulverização contendo dois bicos tipo leque Teejet 110.02 com volume de calda de $200 \mathrm{~L} \mathrm{ha}^{-1}$. O delineamento utilizado foi o de blocos ao acaso, com quatro repetições. As parcelas abrangiam área de $10 \times 10 \mathrm{~m}$, individualizadas com a construção de aceiros mantidos livres da presença de plantas daninhas, evitando assim uma possivel contaminação entre as parcelas pela água das chuvas. As condições edafoclimáticas médias durante a condução do ensaio foram monitoradas e podem ser visualizadas na Tabela 3 .

Após a aplicação dos herbicidas, foram retiradas amostras de solo, por meio de sonda, até a profundidade de $10 \mathrm{~cm}$, para determinação da persistência. Em cada parcela, foram retiradas cinco amostras simples para compor uma amostra composta, perfazendo quatro amostras compostas provenientes de cada repetição. Foram retiradas amostras de solo para determinação da persistência nas seguintes épocas: $0,15,30,45,60,90,120$, 150 e 210 dias após a aplicação dos tratamentos (DAT).

Após a coleta de solo, as amostras foram colocadas em vasos com capacidade de $0,5 \mathrm{~L}$, para a semeadura das plantas bioindicadoras de Cucumis sativus. Os vasos foram colocados em um fitotron ajustado para $25^{\circ} \mathrm{C}$ e fotoperiodo com intensidade luminosa de 35.400 lúmen $\mathrm{m}^{-2}$, por 16 horas. Decorridos
14 dias de emergência (DAE), foram feitas avaliações visuais de fitotoxicidade, atribuindo-se notas de 0-100\%. Além disso, as plantas foram cortadas rente ao solo, para obtenção da massa seca da parte aérea e da área foliar, sendo esta avaliada por meio de aparelho portátil Li-3000C. Os resultados foram comparados aos das plantas que se desenvolveram em solo retirado da testemunha capinada, sendo determinada a persistência dos herbicidas.

Os dados obtidos nos dois ensaios foram submetidos à análise de variância e de regressão, utilizando-se o programa SIGMAPLOT para confecção das curvas de regressão. Para algumas análises, procedeu-se à comparação das médias entre si por meio do teste de Tukey a $5 \%$ de probabilidade.

\section{RESULTADOS E DISCUSSÃO}

\section{Ensaio de lixiviação}

Houve potencial de lixiviação do herbicida sulfentrazone ao longo do perfil dos solos de textura argilosa e textura média (Figura 1 e Tabela 4). O efeito da lixiviação foi mais

Tabela 3 - Dados meteorológicos da região de Araras, durante a condução do experimento

\begin{tabular}{|c|c|c|c|c|}
\hline $\begin{array}{c}\text { Dias após } \\
\text { aplicação dos } \\
\text { herbicidas }\end{array}$ & \multicolumn{3}{|c|}{ Temperatura $\left({ }^{\circ} \mathrm{C}\right)$} & Chuva \\
\cline { 2 - 5 } & T máx. & T mín. & T méd. & $(\mathrm{mm})$ \\
\hline $0-15$ & 34,2 & 20,2 & 27,2 & 61,6 \\
\hline $15-30$ & 31,4 & 18,2 & 24,8 & 67,8 \\
\hline $30-45$ & 31,8 & 18,4 & 25,1 & 44,6 \\
\hline $45-60$ & 29,8 & 20,2 & 25,0 & 61,6 \\
\hline $60-90$ & 32,4 & 18,2 & 25,3 & 24,3 \\
\hline $90-120$ & 30,0 & 18,2 & 24,1 & 25,0 \\
\hline $120-150$ & 29,2 & 18,8 & 24,0 & 70,6 \\
\hline $150-210$ & 29,1 & 16,6 & 22,8 & 36,0 \\
\hline
\end{tabular}

Tabela 2 - Características químicas e físicas da amostra do solo utilizado no experimento

\begin{tabular}{|c|c|c|c|c|c|c|c|c|c|c|c|c|c|c|}
\hline Amostra & $\mathrm{pH}$ & $\mathrm{MO}$ & $\mathrm{P}$ & $\mathrm{K}$ & $\mathrm{Ca}$ & $\mathrm{Mg}$ & $\mathrm{H}+\mathrm{Al}$ & $\mathrm{SB}$ & $\mathrm{CTC}$ & $\mathrm{V}$ & Argila & Silte & Areia \\
\hline LV df & $\left(\mathrm{CaCl}_{2}\right)$ & $\left(\mathrm{g} \mathrm{dm}^{-3}\right)$ & $\left(\mathrm{mg} \mathrm{dm}^{-3}\right)$ & \multicolumn{5}{|c|}{$\left(\mathrm{mmol}_{\mathrm{c}} \mathrm{dm}^{-3}\right)$} & & & $(\%)$ & \multicolumn{3}{|c|}{$\left(\mathrm{g} \mathrm{kg}^{-1}\right)$} \\
\hline $0-10$ & 4,7 & 26 & 4 & 0,8 & 20 & 9 & 29 & 29,8 & 58,8 & 51 & 560 & 240 & 200 \\
\hline $10-20$ & 4,7 & 24 & 2 & 0,7 & 18 & 8 & 29 & 26,7 & 55,7 & 48 & 590 & 220 & 190 \\
\hline
\end{tabular}

LVdf - Latossolo Vermelho Distroférrico. 
Tabela 4 - Valores médios da massa seca da parte aérea de plantas de pepino cultivadas em solos submetidos à aplicação de sulfentrazone e imazapic, seguida de 40 e $80 \mathrm{~mm}$ de chuva

\begin{tabular}{|c|c|c|c|}
\hline \multicolumn{4}{|c|}{ Peso da massa seca $(\mathrm{g})$ - tratamento sulfentrazone } \\
\hline $\begin{array}{l}\text { Profundidade } \\
\text { na coluna } \\
(\mathrm{cm})\end{array}$ & $\begin{array}{c}\text { LVdf } \\
\text { pH 4,7 } \\
\text { argiloso }\end{array}$ & $\begin{array}{c}\text { LVdf } \\
\text { pH 6,0 } \\
\text { argiloso }\end{array}$ & $\begin{array}{l}\text { LVd } \\
\text { pH 5,3 } \\
\text { média }\end{array}$ \\
\hline \multicolumn{4}{|c|}{ Simulação de $40 \mathrm{~mm}$ de chuva } \\
\hline $0-5$ & $0,01 \mathrm{~d}$ & $0,01 \mathrm{c}$ & $0,01 \mathrm{c}$ \\
\hline $5-10$ & $0,01 \mathrm{~d}$ & $0,01 \mathrm{c}$ & $0,01 \mathrm{c}$ \\
\hline $10-15$ & $0,01 \mathrm{~d}$ & $0,01 \mathrm{c}$ & $0,01 \mathrm{c}$ \\
\hline $15-20$ & $0,03 \mathrm{~cd}$ & $0,03 \mathrm{bc}$ & $0,01 \mathrm{c}$ \\
\hline $20-25$ & $0,05 \mathrm{bc}$ & $0,04 \mathrm{ab}$ & $0,02 \mathrm{c}$ \\
\hline $25-30$ & $0,05 \mathrm{bc}$ & $0,05 \mathrm{ab}$ & $0,02 \mathrm{~b}$ \\
\hline $30-35$ & $0,07 \mathrm{ab}$ & $0,06 \mathrm{a}$ & $0,03 \mathrm{~b}$ \\
\hline $35-40$ & $0,09 \mathrm{a}$ & $0,07 \mathrm{a}$ & $0,05 \mathrm{a}$ \\
\hline $\mathrm{CV}(\%)$ & 31,83 & 36,83 & 28,86 \\
\hline \multicolumn{4}{|c|}{ Simulação de $80 \mathrm{~mm}$ de chuva } \\
\hline $0-5$ & $0,01 \mathrm{c}$ & $0,01 \mathrm{~b}$ & $0,01 \mathrm{c}$ \\
\hline $5-10$ & $0,01 \mathrm{c}$ & $0,01 \mathrm{~b}$ & $0,01 \mathrm{c}$ \\
\hline $10-15$ & $0,01 \mathrm{c}$ & $0,01 \mathrm{~b}$ & $0,01 \mathrm{c}$ \\
\hline $15-20$ & $0,01 \mathrm{c}$ & $0,01 \mathrm{~b}$ & $0,01 \mathrm{c}$ \\
\hline $20-25$ & $0,02 \mathrm{bc}$ & $0,02 \mathrm{~b}$ & $0,01 \mathrm{c}$ \\
\hline $5-30$ & $0,02 \mathrm{bc}$ & $0,02 \mathrm{~b}$ & $0,02 \mathrm{~b}$ \\
\hline $30-35$ & $0,04 \mathrm{ab}$ & $0,04 \mathrm{a}$ & $0,02 \mathrm{~b}$ \\
\hline $35-40$ & $0,05 \mathrm{a}$ & $0,05 \mathrm{a}$ & $0,04 \mathrm{a}$ \\
\hline $\mathrm{CV}(\%)$ & 35,73 & 47,01 & 27,01 \\
\hline \multicolumn{4}{|c|}{ Peso da massa seca $(\mathrm{g})$ - tratamento imazapic } \\
\hline \multicolumn{4}{|c|}{ Simulação de $40 \mathrm{~mm}$ de chuva } \\
\hline $0-5$ & $0,03 \mathrm{bc}$ & $0,02 \mathrm{~d}$ & $0,02 \mathrm{c}$ \\
\hline $5-10$ & $0,03 \mathrm{bc}$ & $0,03 \mathrm{~cd}$ & $0,02 \mathrm{c}$ \\
\hline $10-15$ & $0,03 \mathrm{bc}$ & $0,03 \mathrm{~cd}$ & $0,02 \mathrm{c}$ \\
\hline $15-20$ & $0,04 \mathrm{bc}$ & $0,06 \mathrm{ab}$ & $0,03 \mathrm{bc}$ \\
\hline $20-25$ & $0,04 \mathrm{bc}$ & $0,06 \mathrm{ab}$ & $0,03 \mathrm{bc}$ \\
\hline $25-30$ & $0,04 \mathrm{bc}$ & $0,07 \mathrm{ab}$ & $0,04 \mathrm{a}$ \\
\hline $30-35$ & $0,05 \mathrm{~b}$ & $0,07 \mathrm{ab}$ & $0,04 \mathrm{a}$ \\
\hline $35-40$ & $0,07 \mathrm{a}$ & $0,08 \mathrm{a}$ & $0,04 \mathrm{a}$ \\
\hline $\mathrm{CV}(\%)$ & 16,35 & 37,11 & 18,10 \\
\hline \multicolumn{4}{|c|}{ Simulação de $80 \mathrm{~mm}$ de chuva } \\
\hline $0-5$ & $0,04 \mathrm{~b}$ & $0,03 \mathrm{~cd}$ & $0,03 \mathrm{~b}$ \\
\hline $5-10$ & $0,03 \mathrm{~b}$ & $0,02 \mathrm{~d}$ & $0,03 \mathrm{~b}$ \\
\hline $10-15$ & $0,03 \mathrm{~b}$ & $0,02 \mathrm{~d}$ & $0,04 \mathrm{ab}$ \\
\hline $15-20$ & $0,03 \mathrm{~b}$ & $0,02 \mathrm{~d}$ & $0,02 \mathrm{~b}$ \\
\hline $20-25$ & $0,03 \mathrm{~b}$ & $0,05 \mathrm{ab}$ & $0,03 \mathrm{ab}$ \\
\hline $25-30$ & $0,04 \mathrm{~b}$ & $0,04 \mathrm{bc}$ & $0,03 \mathrm{ab}$ \\
\hline $30-35$ & $0,04 \mathrm{~b}$ & $0,05 \mathrm{ab}$ & $0,03 \mathrm{ab}$ \\
\hline $35-40$ & $0,07 \mathrm{a}$ & $0,06 \mathrm{a}$ & $0,05 \mathrm{a}$ \\
\hline $\mathrm{CV}(\%)$ & 28,16 & 23,69 & 29,10 \\
\hline
\end{tabular}

Médias seguidas por letras iguais minúsculas nas colunas, dentro de cada simulação, não diferem significativamente entre si pelo teste de Tukey a $5 \%$ de probabilidade. pronunciado à medida que se aumentou a quantidade de chuva simulada. Não houve diferença entre as lâminas de água na faixa de 0 a $10 \mathrm{~cm}$ de profundidade. Todavia, quando foi aplicada a lâmina de $80 \mathrm{~mm}$, houve controle do bioindicador maior que $80 \%$ aos $30 \mathrm{~cm}$ de profundidade em todos os solos avaliados, refletindo em biomassa de 0,02 g. Nessa profundidade, a lâmina de $40 \mathrm{~mm}$ apresentou controle de $80 \%$ apenas no solo de textura média; já nos solos com textura argilosa compH de 4,7 e 6,0, o controle foi abaixo

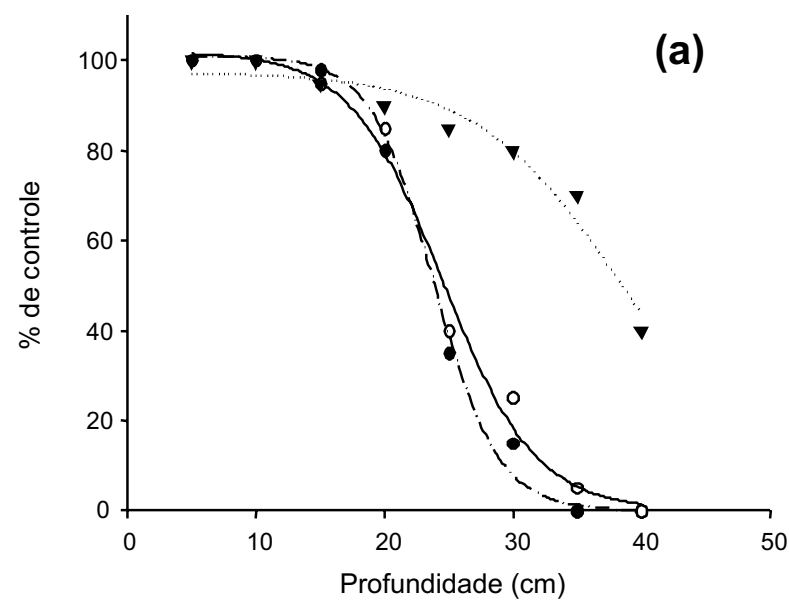

- solo argiloso $(\mathrm{pH} 4,7) \mathrm{y}=99,39 /(1+\exp (-(\mathrm{x}-23,53) /-2,65)) \mathrm{R}^{2}=0,99$ -o-solo argiloso $(\mathrm{pH} 6,0) \mathrm{y}=101,01 /(1+\exp (-(\mathrm{x}-23,87) /-2,48)) \mathrm{R}^{2}=0,99$ ... solo média $\mathrm{pH}(5,3) \mathrm{y}=97,57 /(1+\exp (-(\mathrm{x}-38,79) /-5,86)) \mathrm{R}^{2}=0,98$

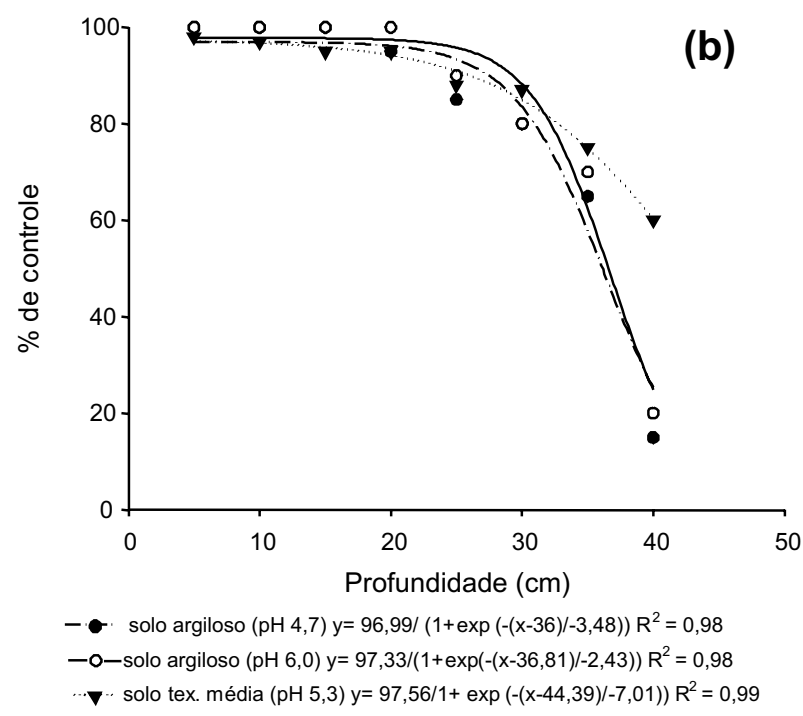

Figura 1 - Lixiviação do herbicida sulfentrazone em solos com diferentes pHs, com a simulação de 40 (A) e 80 mm (B) de chuva. 
de $20 \%$, com plantas apresentando, em ambos os casos, biomassa seca de 0,05 g. Foi constatada atividade residual do herbicida até $40 \mathrm{~cm}$ de profundidade, na precipitação de $80 \mathrm{~mm}$, nos solos de textura média e argilosa, ao passo que com precipitação de $40 \mathrm{~mm}$ constatou-se atividade residual apenas no solo com textura média, porém em baixa intensidade, já que os efeitos sobre o bioindicador foram pouco pronunciados. Embora o valor da constante de dissociação do sulfentrazone seja elevado (pKa $=6,6)$, prevalecendo a existência de moléculas na forma não dissociada, a lixiviação foi ligeiramente maior em solo com $\mathrm{pH}$ de 6,0 e muito maior em solo com textura média. Além das características físico-químicas das moléculas (pKa, S, Kow), a movimentação das moléculas depende também dos atributos físicos, químicos e biológicos do solo, como textura, mineralogia, teor de matéria orgânica, $\mathrm{pH}, \mathrm{CTC}$, atividade microbiana, entre outros. De acordo com Zobiole et al. (2007), os efeitos do sulfentrazone na soja foram mais acentuados com o aumento da densidade do solo.

Reddy \& Locke (1998), investigando a sorção do sulfentrazone correlacionada com dois tipos de solo (médio e pesado) e de manejo (convencional e plantio direto), observaram que, independentemente do tipo de manejo, a taxa de sorção foi maior no solo argiloso e a dessorção se deu de forma lenta. Grey et al. (1997), também analisando a sorção do herbicida sulfentrazone, observaram que esta é muito influenciada pelo $\mathrm{pH}$. A sorção geralmente diminui em resposta a um aumento do $\mathrm{pH}$, especialmente quando os valores excedem o pKa do herbicida $(6,56)$, uma vez que passa a predominar a forma ionizada; contudo, abaixo desse valor, com o aumento da forma molecular, a sorção aumenta. Rossi et al. (2005) observaram que sob precipitação de $90 \mathrm{~mm}$ em Neossolo Quartzarênico textura arenosa ( $\mathrm{pH} \mathrm{CaCl} \mathrm{Cl}_{2}$ de 4,3 e $6 \mathrm{~g} \mathrm{dm}^{-3}$ de MO) o sulfentrazone formou uma banda de arraste de até $12,5 \mathrm{~cm}$, e em Nitossolo Vermelho textura média $\left(\mathrm{pH} \mathrm{CaCl}_{2}\right.$ de 5,4 e $21 \mathrm{~g} \mathrm{dm}^{-3} \mathrm{de}$ $\mathrm{MO}$ ), até os $7,5 \mathrm{~cm}$.

Em relação ao imazapic (Figura 2 e Tabela 4), na precipitação de $40 \mathrm{~mm}$ de chuva, observou-se atividade da molécula inibindo o desenvolvimento do bioindicador em torno de $80 \%$ na faixa entre 0 e $10 \mathrm{~cm}$ de profundidade no solo de textura média; em $30 \mathrm{~cm}$ de profundidade a porcentagem de controle chega a $37 \%$, com biomassa de 0,04 g. No solo de textura argilosa com $\mathrm{pH} 4,7$, é possivel observar que em $30 \mathrm{~cm}$ de profundidade o controle é de aproximadamente $27 \%$; já no solo com $\mathrm{pH}$ de 6,0 é de $31 \%$, ou seja, ligeiramente superior ao do solo com pH de 4,7, com biomassa de 0,04 e $0,07 \mathrm{~g}$, respectivamente. Na simulação de
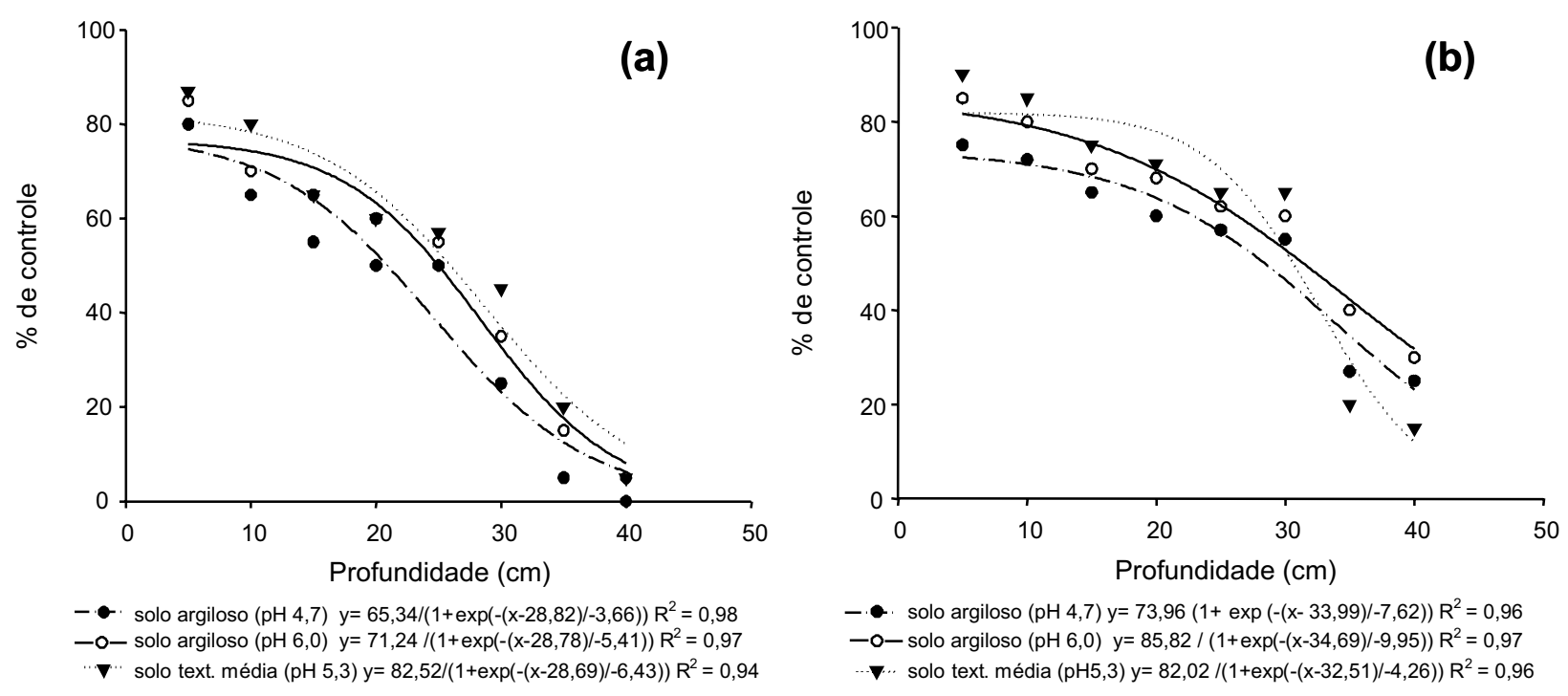

Figura 2 - Lixiviação do herbicida imazapic em solos com diferentes pHs, com a simulação de 40 (A) e 80 mm (B) de chuva. 
$80 \mathrm{~mm}$ de chuva, o controle do bioindicador foi maior ao longo do perfil dos solos. No caso do solo com textura média, observa-se que a $30 \mathrm{~cm}$ de profundidade o controle foi semelhante ao do solo com textura argilosa e $\mathrm{pH}$ de 6,0: em torno de 53\%. No solo com textura argilosa com $\mathrm{pH}$ de 4,7 , por sua vez, o controle foi de aproximadamente 46 e $23 \%$ nas profundidades de 30 e $40 \mathrm{~cm}$, respectivamente. Desse modo, quando se elevou o $\mathrm{pH}$ para 6,0, verificou-se ligeiro aumento no controle do bioindicador (Figura 2). Isso é esperado, já que os herbicidas do grupo das imidazolinonas que predominam na forma aniônica (-COO-) em $\mathrm{pH}$ de $7 \pm 2$ são repelidos pelas cargas negativas dos coloides minerais e orgânicos do solo. Em $\mathrm{pH}$ de 6,0 o imazapic apresenta-se muito dissociado e não se espera adsorção significativa se o mecanismo de adsorção for exclusivamente iônico. Segundo Inoue et al. (2007), quando se simula precipitação de $40 \mathrm{~mm}$ de água em um solo classificado como Latossolo Vermelho distrófico $\left(880,20\right.$ e $100 \mathrm{~g} \mathrm{~kg}^{-1} \mathrm{de}$ areia, silte e argila, respectivamente; $\mathrm{pH}_{(\mathrm{CaCl} / 2)}=$ 4,5 e 5,19 $\mathrm{g} \mathrm{dm}^{-3} \mathrm{de} \mathrm{C}$ ), dependendo da dose e do bioindicador utilizado, a lixiviação de imazapic vai até a camada de 10-15 ou $15-20 \mathrm{~cm}$.

Em trabalho anterior, verificou-se que o herbicida imazapyr com $80 \mathrm{~mm}$ de chuva apresentou fitotoxicidade até $25 \mathrm{~cm}$ de profundidade em solo argiloso com $\mathrm{pH}$ de 4,7; à medida que o indice pluviométrico aumentou, a profundidade de ação também aumentou (Monquero et al., 2008). A atividade biológica e o seu movimento no solo são grandemente influenciados por numerosos fatores ambientais. Entre esses fatores, tem-se demonstrado que a textura, o tipo de argila, a umidade e o $\mathrm{pH}$ influenciam diretamente a adsorção e, consequentemente, a mobilidade do imazapyr no perfil do solo (Michael \& Neary, 1993; Ismail \& Ahmad, 1994). Wehtje et al. (1987) observaram maior mobilidade do imazapyr em solos argilosos e, também, que essa mobilidade diminuiu com a redução da umidade e do $\mathrm{pH}$ do solo. Entretanto, resultados contrários foram observados por Vizantinopoulos \& Lolos (1994), que encontraram maior mobilidade no solo com menor teor de argila. Essa diferença de mobilidade pode estar relacionada a fatores que estariam agindo sobre os fenômenos adsortivos, como as características mineralógicas e teor e o tipo de matéria orgânica dos solos estudados. Pusino et al. (1997) constataram que a adsorção do imazapyr é fortemente influenciada pelo $\mathrm{pH}$ e pela carga do componente adsorvente e que a presença de óxidos de ferro amorfo e matéria orgânica, a $\mathrm{pH}<5$, é efetiva na sua retenção.

A adsorção dos herbicidas do grupo das imidazolinonas, que se apresentam como moléculas aniônicas, geralmente aumenta à medida que o pH diminui (Renner et al., 1988; Stougaard et al., 1990; Loux \& Reese, 1993). A adsorção pode ocorrer por ligações hidrofóbicas, por pontes de hidrogênio, por forças de van der Walls, por ligações por meio de metais e ligações eletrostáticas. Stougaard et al. (1990), utilizando imazethapyr e imazaquin em solos com $\mathrm{pH}$ de 7 , sugerem que alguma forma de adsorção física do produto aos coloides do solo pode ocorrer. Assim, fatores como quantidade e tipo de argila e quantidade de matéria orgânica influenciam o processo de adsorção e, consequentemente, o de lixiviação.

Deve-se esperar uma correlação inversa entre o potencial de lixiviação e a capacidade de adsorção do solo, ou seja, solos argilosos tendem a adsorver mais as moléculas de herbicidas, enquanto nos arenosos a lixiviação pode ser favorecida. Além disso, o movimento de agroquímicos através do perfil do solo é influenciado pela infiltração de água; portanto, para os herbicidas potencialmente lixiviáveis, espera-se correlação positiva entre a precipitação e a lixiviação. Em razão disso, precipitações intensas podem promover a lixiviação desses produtos e contaminar as águas subsuperficiais.

A lixiviação de pesticidas no perfil do solo tem implicações diretas no potencial de contaminação de recursos hídricos do subsolo, já que, uma vez retirados das camadas superficiais do solo, onde há maior teor de matéria orgânica e atividade microbiana, a sua persistência no ambiente pode ser intensamente prolongada (Sarmah et al., 1998; Costa et al., 2000; Prata et al., 2001).

Desse modo, os resultados obtidos sugerem que ambos os herbicidas estão sujeitos à lixiviação, e houve tendência de interferência do $\mathrm{pH}$ nesse processo. $\mathrm{O}$ solo argiloso com $\mathrm{pH}$ 
de 6,0 apresentou maior potencial de lixiviação que o mesmo solo com $\mathrm{pH}$ de 4,7, sendo essa diferença mais pronunciada para o herbicida imazapic.

\section{Ensaio de persistência}

Para o herbicida sulfentrazone, observase, que aos 120 dias após a aplicação em campo, o resíduo no solo foi capaz de controlar 80 e $77,5 \%$ do biondicador na maior e menor dose, respectivamente. Aos 210 dias após a aplicação, a atividade residual diminuiu de maneira significativa, independentemente da dose utilizada, causando leve amarelecimento das folhas, não chegando a afetar o crescimento e desenvolvimento das plantas de pepino (Tabela 5). Na Tabela 6, a área foliar do bioindicador reforça esse resultado. Segundo Rodrigues \& Almeida (2005), um período de 18 meses após a aplicação de sulfentrazone é exigido para a rotação com culturas sensiveis, como o algodão. A meia-vida em solos brasileiros é, em média, de 180 dias. Blanco \& Velini (2005) observaram que o herbicida sulfentrazone apresenta grande persistência no solo, prejudicando de forma significativa o desenvolvimento das culturas sucedâneas de milheto cv. Italiano e aveia cv. Branca e da cultura do trigo $\mathrm{cv}$. IAC 24, esta somente na maior dose $\left(1,2 \mathrm{~kg} \mathrm{ha}^{-1}\right)$; contudo, não prejudica o desenvolvimento das culturas de girassol cv. Uruguay 1 e feijão cv. Carioca.

O solo onde se realizou o ensaio apresentou altos teores de matéria orgânica ( $\left.36 \mathrm{~g} \mathrm{dm}^{3}\right)$ e argila (560 $\mathrm{g} \mathrm{kg}^{-1}$ ); isso, em conjunto com a porcentagem do herbicida que estava na forma molecular, em função da constante de ionização do sulfentrazone e do $\mathrm{pH}$ do solo, faz com que haja uma tendência de favorecer a sorção do herbicida aos coloides do solo (Grey et al., 1997). No entanto, como a aplicação do herbicida foi caracterizada pelas chuvas frequentes e altas temperaturas (Tabela 3), essa situação não beneficiou a sorção do herbicida pelos coloides do solo; ao contrário, favoreceu a sua permanência na solução e a disponibilidade para os processos dissipativos e de lixiviação (Walker \& Allen, 1984).

Em relação ao imazapic, o controle do bioindicador foi maior que $80 \%$ no solo amostrado até 45 DAA; já na coleta feita aos 60 DAA, o

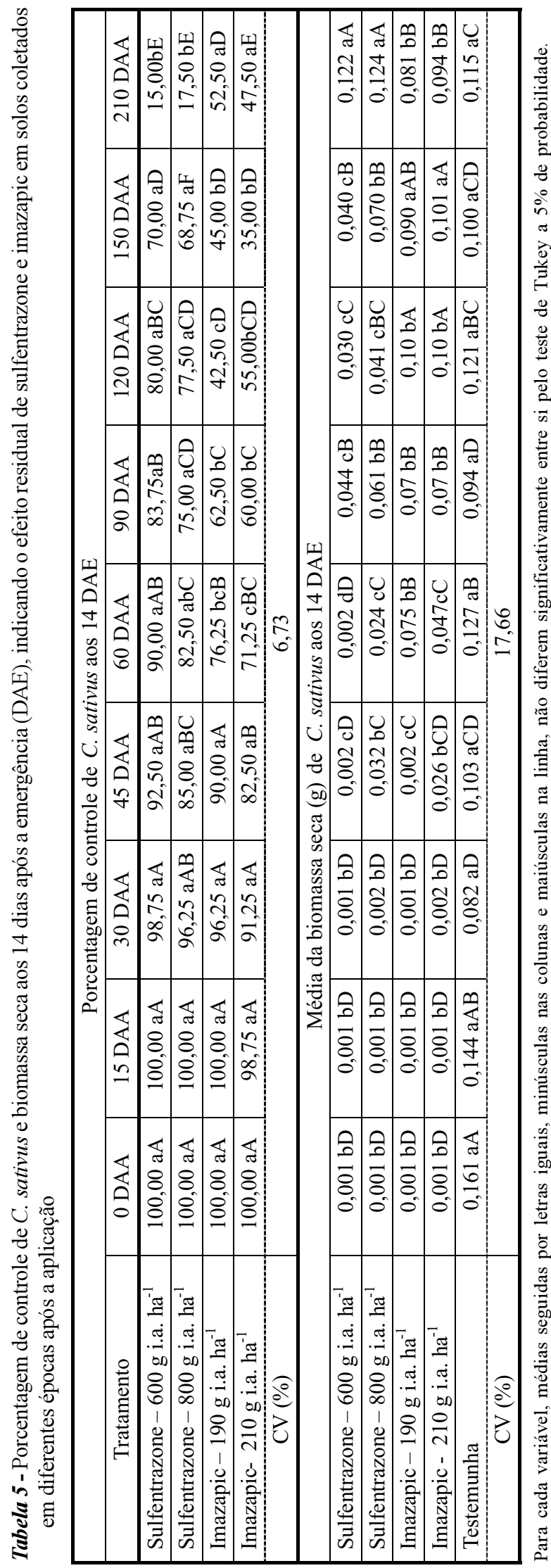

Planta Daninha, Viçosa-MG, v. 28, n. 1, p. 185-195, 2010 
Tabela 6 - Média da área foliar $\left(\mathrm{cm}^{2}\right)$ do biondicador C. sativus em diferentes épocas após aplicação dos herbicidas sulfentrazone e imazapic

\begin{tabular}{|l|c|c|c|c|c|c|c|c|c|}
\hline \multicolumn{8}{|c|}{ Área foliar de controle de C. sativus aos 14 DAE } \\
\hline \multicolumn{1}{|c|}{ Tratamento } & 0 & 15 & 30 & 45 & 60 & 90 & 120 & 150 & 210 \\
\hline Sulfentrazone-600 g i.a. ha ${ }^{-1}$ & $0,0 \mathrm{~b}$ & $0,0 \mathrm{~b}$ & $0,0 \mathrm{c}$ & $2,94 \mathrm{~b}$ & $2,04 \mathrm{c}$ & $3,71 \mathrm{c}$ & $3,49 \mathrm{c}$ & $3,87 \mathrm{c}$ & $18,75 \mathrm{~b}$ \\
\hline Sulfentrazone-800 g i.a. ha $^{-1}$ & $0,0 \mathrm{~b}$ & $0,0 \mathrm{~b}$ & $2,04 \mathrm{~b}$ & $3,56 \mathrm{~b}$ & $2,78 \mathrm{bc}$ & $3,75 \mathrm{c}$ & $3,15 \mathrm{c}$ & $4,28 \mathrm{c}$ & $17,81 \mathrm{~b}$ \\
\hline${\text { Imazapic - 190 g i.a. ha } \text { ha }^{-1}}^{-1}$ & $0,0 \mathrm{~b}$ & $0,0 \mathrm{~b}$ & $2,00 \mathrm{~b}$ & $2,81 \mathrm{~b}$ & $3,75 \mathrm{~b}$ & $4,57 \mathrm{c}$ & $5,89 \mathrm{~b}$ & $7,19 \mathrm{~b}$ & $8,16 \mathrm{c}$ \\
\hline Imazapic- 210 g i.a. ha $^{-1}$ & $0,0 \mathrm{~b}$ & $0,0 \mathrm{~b}$ & $2,71 \mathrm{~b}$ & $3,75 \mathrm{~b}$ & $3,81 \mathrm{~b}$ & $5,89 \mathrm{~b}$ & $6,78 \mathrm{~b}$ & $8,37 \mathrm{~b}$ & $8,49 \mathrm{c}$ \\
\hline Testemunha & $25,89 \mathrm{a}$ & $32,15 \mathrm{a}$ & $33,45 \mathrm{a}$ & $28,9 \mathrm{a}$ & $29,78 \mathrm{a}$ & $30,15 \mathrm{a}$ & $24,89 \mathrm{a}$ & $26,49 \mathrm{a}$ & $27,19 \mathrm{a}$ \\
\hline \multicolumn{1}{|c|}{ CV (\%) } & 8,48 & 14,23 & 8,58 & 18,22 & 6,08 & 4,40 & 6,41 & 5,14 & 8,99 \\
\hline
\end{tabular}

Médias seguidas por letras iguais minúsculas nas colunas não diferem significativamente entre si pelo teste de Tukey a 5\% de probabilidade.

controle foi de 76,25 e $71,25 \%$ na maior e menor dose, respectivamente. Na última avaliação, observaram-se plantas com sintomas de amarelecimento das folhas e menor porte, mas isso não chegou a comprometer o desenvolvimento do bioindicador (Tabelas 5 e 6). Comparando o imazapic com o sulfentrazone, observou-se que eles apresentaram residual semelhante até 45 DAA, todavia, dos 60 aos 150 DAA, houve menor atividade residual no solo do imazapic; a partir deste periodo (150 aos 210 DAA), o sulfentrazone apresentou queda acentuada da atividade residual no solo e o imazapic manteve, nesse intervalo, a mesma atividade residual que apresentou aos 120 DAA. A persistência de herbicidas do grupo químico das imidazolinonas, ao qual pertence o imazapic, é influenciada por propriedades do solo, como o $\mathrm{pH}$, a umidade, o teor de matéria orgânica e a textura (Stougaard et al., 1990). O herbicida imazapic apresenta atividade residual no solo, o que lhe confere ação herbicida sobre as sementeiras das plantas daninhas. A utilização desse produto na preparação de área em solos arenosos e/ou num período menor que 30 dias antes do plantio pode acarretar injúria à cultura da cana-de-açúcar (Rodrigues \& Almeida, 2005). Para outros herbicidas do grupo das imidazolinonas, recomenda-se um intervalo de 300 dias entre a aplicação do imazaquin e a semeadura do milho em rotação (Rodrigues \& Almeida, 2005). Quanto ao imazethapyr, recomenda-se não cultivar o milho em sucessão à soja onde foi aplicado esse herbicida.

Conclui-se que o sulfentrazone, apesar de apresentar elevada atividade no solo até 150 DAA, apresenta dissipação acentuada a partir desse período; já a atividade do imazapic não é tão elevada a partir dos 90 DAA, mas mantém aos 210 DAA maior atividade que o sulfentrazone.

\section{LITERATURA CITADA}

ASOCIATION LATINOAMERICANA DE MALEZAS ALAM. Recomendaciones sobre unificación de los sistemas de evaluación em ensayos de control de malezas. ALAM, v. 1, p. $35-38,1974$

BLANCO, H. G. Destino, comportamento e resíduos dos herbicidas no solo. O Biológico, v. 45, n. 11, p. 225-248, 1979.

BLANCO, F. M. G.; VELINI, E. D. Persistência do herbicida sulfentrazone em solo cultivado com soja e seu efeito em culturas sucedâneas. Planta Daninha, v. 23, n. 4, p. 693-700, 2005.

CARTER, A. D. Herbicide movement in soils: principles, pathways and processes. Weed Res., v. 40, n. 1, p. 113-122, 2000 .

COSTA, E. A. D.; GELMINI, G. A.; ZAMBON, S. Avaliação de isoxaflutole aplicado isoladamente ou em mistura de tanque no nivelamento do solo para controle pré-emergente de infestantes em cana-planta. In: CONGRESSO BRASILEIRO DA CIÊNCIA DAS PLANTAS DANINHAS, 22., 2000, Foz do Iguaçu. Resumos... Londrina: SBCPD, 2000. p. 295

EMPRESA BRASILEIRA DE PESQUISAAGROPECUÁRIA - EMBRAPA. Sistema brasileiro de classificação de solos. Brasília: 1999. 412 p.

FMC Corp. Technical bulletin of sulfentrazone. Philadelphia: 1995. 6 p.

GREY, T. L. et al. Sulfentrazone adsortion and mobility as affected by soil and pH. Weed Sci., v. 45, n. 4, p. 733-738, 1997. 
HULTING, A. G. et al. Soybean (Glycine $\max$ (L.) Merr.) cultivars tolerance to sulfentrazone. Crop Protec., v. 20, n. 8, p. $679-683,2001$.

INOUE, M. H. et al. Calagem e o potencial de lixiviação de imazaquin em colunas de solo. Planta Daninha, v. 20, n. 1, p. $125-132,2002$.

INOUE, M. H. et al. Potencial de lixiviação de imazapic e isoxaflutole em colunas de solo. Planta Daninha, v. 25, n. 3, p. 547-555, 2007.

ISMAIL, B. S.; AHMAD, A. R. Attenuation of the herbicidal activities of glufosinate ammonium and imazapyr in two soils. Agric. Ecosyst. Environ., v. 47, n. 4, p. 279-285, 1994.

LOUX, M. M.; REESE, K. D. Effect of soil type and $\mathrm{pH}$ on persistence and carriover of imidazolinone herbicides.

Weed Sci., v. 37, p. 452-58, 1993.

LOUX, M. M.; LIEBL, R. A.; SLIFE, F. W. Adsorption of imazaquin and imazethapyr on soils, sediments, and selected adsorbents. Weed Sci., v. 37, p. 712-718, 1989.

MONQUERO, P. A. et al. Potencial de lixiviação de herbicidas no solo submetidos a diferentes simulações de precipitação.

Planta Daninha, v. 26, n. 2, p. 403-409, 2008.

MICHAEL, J. L.; NEARY, D. G. Herbicide dissipation studies in southern forest ecosystems. Environ. Toxicol. Chem., v. 12, n. 3 , p. $405-410,1993$.

PROCÓPIO, S. D. et al. Efeito da irrigação inicial na profundidade de lixiviação do herbicida s-metolachlor em diferentes tipos de solo. Planta Daninha, v. 19, n. 3, p. $409-417,2001$.

PRATA, F. et al. Glyphosate sorption and desorption in soils with different phosphorous levels. Sci. Agric., v. 60, n. 1, p. 175-180, 2003.

PRATA, F. et al. Degradação e sorção de ametrina em dois solos com aplicação de vinhaça. Pesq. Agropec. Bras., v. 36, n. 7, p. $975-981,2001$

PUSINO, A.; PETRETTO, S.; GESSA, C. Adsorption and desorption of imazapyr by soil . J. Agric. Food Chem., v. 45, n. 3, p. 1012-1016, 1997.

REDDY, K. N.; LOCKE, M. A. Sulfentrazone sorption, desorption, and mineralization in soils from two tillage systems. Weed Sci., v. 46, n. 4, p. 494-500, 1998.

RENNER, K. A.; MEGGITT, W. F. \& PENNER, D. Effect of soil $\mathrm{pH}$ on imazaquin and imazethapyr adsorption to soil and phytotoxicity to corn (Zea mays). Weed Sci., v. 36, p. 78-83, 1988.
REGITANO, J. B. et al. Retention of imazaquin in soil. Environ. Toxicol. Chem., v. 16, n. 3, p. 397-404, 1997.

ROCHA, W. S. D. et al. Influência do pH na sorção de imazaquin em um Latossolo Vermelho acriférrico. R. Bras. Ci. Solo, v. 24, n. 3, p. 649-655, 2000.

RODRIGUES, B. N.; ALMEIDA, F. S. Guia de herbicidas. 5.ed. Londrina: Edição dos Autores, 2005. 591 p.

ROSSI, C. V. S.; ALVES, P. L. C. A.; MARQUES JUNIOR, J. Mobilidade do sulfentrazone em Latossolo Vermelho e em Chernossolo. Planta Daninha, v. 23, n. 4, p. 701-710, 2005.

STOUGAARD, R. N.; SHEA, P. J.; MARTIN, A. R. Effect of soil type and $\mathrm{pH}$ on adsorption, mobility, and efficacy of imazaquin and imazethapyr. Weed Sci., v. 38, p. 67-73, 1990

SARMAH A.; KOOKANA, R.; ALSTON, A. Fate and behaviour of triasulfuron, metsulfuron-methyl and chlorsulfuron in the Australian soil environment: a review. Aust. J. Agric. Res., v. 49, n. 5, p. 775-790, 1998.

SOUTHWICK, L. M. et al. Potential influence of sugarcane cultivation on estuarine water quality of Louisiana's gulf coast. J. Agric. Food Chem., v. 50, n. 15, p. 4393-4399, 2002

TANABE, A. et al. Seasonal and special studies on pesticides residues in surface eaters of the Shinano river in Japan. J. Agric. Food Chem., v. 49, n. 7, p. 3847-3852, 2001

VELINI, E. D. Comportamento de herbicidas no solo. In: SIMPÓSIO NACIONAL SOBRE MANEJO DE PLANTAS DANINHAS EM HORTALIÇAS, 1992, Botucatu.

Resumos... Botucatu: 1992. p. 44-64.

VIVIAN, R. et al. Persistência e lixiviação de ametryn e trifloxysulfuron-sodium em solo cultivado com cana-de-açúcar. Planta Daninha, v. 25, n. 1, p. 111-124, 2007.

VIZANTINOPOULOS, S.; LOLOS, P. Persistence and leaching of the herbicide imazapyr in soil. Bull. Environ. Contam. Toxicol., v. 52, p. 404-410, 1994.

WALKER A.; ALLEN, J. G. Influence of soil and environmental factors on pesticide. Soil Crop Protec. Chem., v. 27 , n. 1 , p. $27-32,1984$.

ZOBIOLE, L. H. S. et al. Efeito da compactação do solo e do sulfentrazone sobre a cultura da soja em duas condições de água no solo. Planta Daninha, v. 25, n. 3, p. 537-545, 2007.

WEBER, B. J.; WILKERSON, G. G.; REINHARDT, C. F. Calculating pesticide sorption coefficients $(\mathrm{Kd})$ using selected soil properties. Chemosphere, v. 55, n. 2, p. 157-166, 2004.

WEHTJE, G. et al. Sorption and mobility of sulfometuron and imazapyr in five Alabama soils. Weed Sci., v. 35, n. 6, p. 858-864, 1987. 